a reaction that is non-essential in the short term for the survival of the cell, and that as one consequence of this primary injury there is a secondary disturbance, for example, the entry of sodium and water into the cell. It is this secondary disturbance which is prevented so long as phenergan is present. It seems that the primary injury caused by carbon tetrachloride will continue in force, after its concentration has dropped, until the vital constituents of the damaged system are re-synthesized. This process appears to take up to $48 \mathrm{hr}$.

The hypothetical secondary disturbance could be associated with the breakdown of phosphoprotein, a system which $\mathrm{Judah}^{5}$ has shown to be sensitive to the action of phenergan and has postulated as part of the mechanism controlling cellular water and electrolyte movements.

The reason for stating that the primary site of attack of carbon tetrachloride is a system not immediately essential for the life of the cell is that, in the presence of phenergan, the damage caused by carbon tetrachloride is reversible. It is clear that this conclusion carries with it some important implications, including therapeutical possibilities.

We are grateful to Sir Roy Cameron and Prof. C. Rimington for their advice and encouragement. One of us (K. R. R.) is indebted to the Medical Research Council for a grant for assistance.

K. R. REES

W. G. SPECTOR

Departments of Chemical Pathology and Morbid Anatomy

University College Hospital Medical School, London.

${ }^{2}$ Rees, K. R., Sinha, K. P., and Spector, W. G., J. Path. Bact. (in the press).

${ }^{2}$ Rees, K. R., and Sinha, K. P., J. Path. Bact., 80, 297 (1960).

${ }^{3}$ Recknagel, R. O., and Anthony, D. D., J. Biol. Chem., 234, 1052 (1959).

4 Recknagel, R. O., and Litteria, M. O., Amer. J. Path., 36, 521 (1960)

${ }^{5}$ Judah, J. D., Nature, 185, 390 (1960).

\section{Alloxan and Hypersensitivity}

During the course of another investigation, it was found that a diabotogenic dose of alloxan $(175-200 \mathrm{mgm} . / \mathrm{kgm} \text {. })^{1}$ protects approximately 50 per cent of rats sensitized to horse serum and later injected intravenously with this antigen. The time of death was lengthened in those rats suffering lethal shock. Controls consistently showed $0-10$ per cent survivors.

Rats were of Sprague-Dawley strain, sensitized by a single intraperitoneal injection of a mixture of horse serum and $H$. pertussis. Alloxan was injected subcutaneously into the sensitized rats just prior to, or four days before, challenge with horse serum. Of the various routes tested, the subcutaneous route for injection of alloxan proved the least toxic. The purpose of this communication is to describe some aspects of the effect of alloxan on hypersensitivity reactions in the rat and guinea pig.

One unit of insulin, injected subcutaneously into alloxan-treated sensitized rats $1 \mathrm{hr}$. before challenge, partially reversed the protective effect of the alloxan. This arnount of insulin also increased the speed with which death occurred in untreated sensitized controls (Fig. 1). Ganley ${ }^{2}$ recently reported similar findings in mice.

In the guinea pig, alloxan injected either intraperitoneally or subcutaneously at $300 \mathrm{mgm}$. $/ \mathrm{kgm}$. body

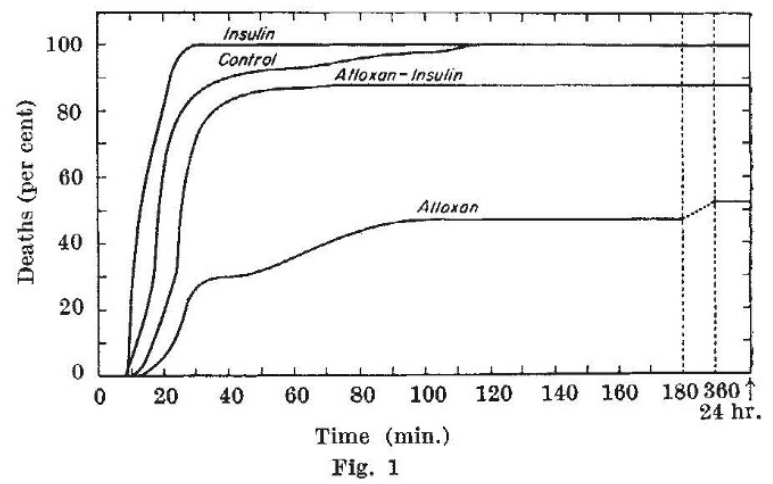

weight four days prior to challenge reduced the size and intensity of the skin reaction to PPD in animals sensitized by injection of killed $M$. tuberculosis in paraffin oil emulsion. Long, Miles and Perry found a similar action of alloxan in guinea pigs infected with living $B C G^{3}$. Alloxan did not protect against either 'immediate' or 'delayed' type anaphylaxis. However, it did appear to give protection during the first $24 \mathrm{hr}$. to the type of shock induced by intraperitoneal challenge with old tuberculin. Failure to protect from anaphylactic shock in the guinea pig may be due to the very swift occurrence of emphysema of the lungs and death from bronchospasm.

The protective effect of a diabetogenic dose of alloxan in rat anaphylaxis and delayed skin hypersensitivity in the guines pig, with its reversal in the rat by insulin, suggests the involvement of a lack of insulin or an excess of glucose. We have evidence that large amounts of glucose $(4 \mathrm{gm} . / \mathrm{kgm} . \quad \times 2)$ injected intraperitoneally prior to challenge gives at least some degree of protection.

George E. Thompson

Wallace Laboratories,

New Brunswick,

New Jersey.

${ }^{1}$ Kass, E. H., and Waisbren, B. A., Proe. Soc. Exp. Biol. Med., 60, 303 (1945).

Ganley, O. H., and Robinson, H. J., Fed. Proc, (March 1959).

${ }^{3}$ Long, D. A., Miles, A. A., and Perry, W. I. M., Lancet, ii, 902 (1951).

\section{ANATOMY}

\section{Function of the Fotal Thyroid of the Rabbit with regard to Cholesterol Metabolism studied by Fotal Thyroidectomy}

IN earlier communications, it was reported that the fotal pituitary-thyroid system influenced cholesterol and fat metabolism. Following removal of this system, a significant rise in the serum cholesterol occurred ${ }^{1}$, and also in the fat content of the foetal liver'. The technique for removing the foetal pituitary and thyroid involves decapitation of the foetus either through the neck to remove both the thyroid as well as the pituitary, or through the mouth to preserve the thyxoid. It has already been shown that this operation has no significant effect on the weight development of the foetus ${ }^{2-4}$, but it may be objeoted that the metabolic changes may be the result of removing structures other than the pituitary and the thyroid, such as the brain.

To overcome this objection and to investigate this problem further, the foetal thyroid was removed 